\title{
An Integrated Design-Based Learning Management Model to Promote Thai Undergraduate Computational Thinking Skills and Programming Proficiency
}

\author{
https://doi.org/10.3991/ijep.v12i1.27603 \\ Phattharapol Prommun ${ }^{1}$, Thiyaporn Kantathanawat ${ }^{1}(\varpi)$, Paitoon Pimdee ${ }^{1}$, \\ Thanate Sukkamart ${ }^{2}$ \\ ${ }^{1}$ King Mongkut's Institute of Technology Ladkrabang (KMITL), Bangkok, Thailand \\ ${ }^{2}$ Prince of Songkla University, Pattani Campus, Hat Yai, Thailand \\ thiyaporn.ka@kmitl.ac.th
}

\begin{abstract}
The study applied concepts of computational thinking, waterfall programming, and design-based learning management (DBLM) combined with a participatory action research (PAR) methodology to obtain an integrated learning management model (LMM) designed as a base to promote computational thinking skills (CTS) and programming proficiency. The study used three groups consisting of 21 volunteer computer education undergraduate students, three teachers, and three computer studies graduates from the Computer Studies Department of the Faculty of Education at Dhonburi Rajabhat University in Thailand. To verify the model, nine educational experts conducted an assessment of the proposed model, and determined that the evaluation standards were overall at a high level $(\bar{x}=4.23, \mathrm{SD}=0.44)$, with the experts feeling that the integration of the DBLM computational thinking framework, the Waterfall programming conceptual framework, and the PAR meeting the study's stated objectives at the highest level $(\bar{x}=4.56, \mathrm{SD}=0.53)$. The proposed model is best undertaken in five week sessions of five hours each using five exercises per week. Activity effectiveness is best measured by taking notes, worksheets, and practicing the learned skills. In conducting this research, there may be obstacles from learners who may withdraw during research due to personal activities or becoming discouraged in learning activities based on a five-week schedule, preventing them from participating every time.
\end{abstract}

Keywords - computational thinking, design-based learning, participatory action research, programming, Thailand

\section{Introduction}

Globally, student computational thinking skills (CTS) have gained significant importance, with scholars now noting the potential for CTS in improving students' problem-solving skills and preparation for the $21^{\text {st }}$-century technology-driven economies [1]. Moreover, researchers have reported that CTS is a component of an individual's universal competence, which when combined with their analytical thinking ability and 
logical reasoning serves as an essential pillar in a contemporary educational curriculum [2], [3]. However, CTS is not a new idea as its roots can be found as far back as 1980 when Seymour Papert discussed the term 'computational thinking,' as a constructionist approach to education. Some years later in 2006, Wing elaborated on CTS as a method to bring computer science to all levels of education [4] - [6]. Papert's CT also focused on the computer's nature as a powerful meta-tool for turning the abstract into concrete solutions, with the potential to be used across all disciplines [7].

In other international studies, the essential nature and increasing importance of CTS in a student's education was reported in Denmark. However, the researchers concluded that educators face many difficulties teaching CTS and are mostly illprepared at teaching it [8]. In Taiwan, CTS has also become a topic of intense debate in student education, with researchers noting the critical requirement for CTS teacher pedagogical content training [9].

In Thailand, computer programming has been recognized as an essential skill of learners in a 21 st-century education society. In one example of this focus, computer studies program students in the Faculty of Education at Thonburi Rajabhat University (Thailand) are taught CTS through learning to write code, while also exploring critical thinking and problem-solving skills. However, after a review of the results from these classes from 2016-2020, we determined that of the 135 students enrolled in objectoriented programming courses, 60 had higher grades point averages (GPAs) than the average, while sadly, $44.44 \%$ from the observations showed us that the students were unable to solve problems from the problems given by the teacher.

Therefore, the development of problem-solving and programming should provide guidelines for teaching and learning that are appropriate for the learners who are the owners of the problems. As each student has different learning behaviors, the instructor must be competent in various subjects using learning management tools to reinforce and increase the desired learning behaviors [10].

As such, we further identified the Waterfall Model as a well-tested and easy-to-use process for teaching and learning programming [11]. The Waterfall Model has been used often in Thailand in teaching software engineering courses as its conceptual design allows a sequence of stages from which the output of each stage becomes the input for the next stage [12]. It is also one of the most recognized models for software and programming education in Thailand.

Another easily recognized and often used research methodology that is suitable for solving research problems is participatory action research (PAR), whose fundamental focus is engaging both students and instructors at the identification of problems and joint problem resolution [10], [13], [14].

Therefore, having identified the significant and growing importance of CTS, we additionally undertook an analysis of what readily available tools and methods were available to integrate into a CTS learning management model (LMM) that can address the problem of lack of CTS. Moreover, we sought an LMM that would encourage students to embrace CTS and the related required coding skills. Therefore, we hope that the results of this research help apply an integrated LMM as a base design to promote CTS and programming ability. 


\section{Literature review}

\subsection{Designed-based learning (DBL)}

Design-based learning management is a learning management activity that integrates interdisciplinary content, allowing students the ability to take part in the process of development, creation, and evaluation of the designed task. In Australia, DBL is used in engineering curriculums to help students become self-directed, which potentially enhances their abilities at obtaining career and life-long learning skills [15]. Moreover, DBL can serve as an effective approach to learning that is centered on a design problem-solving structure adopted for a problem-oriented project-based education [16]. However, DBL in Thailand is a recent innovation and newer form of instructional management involving interdisciplinary integration requiring creativity and technological innovation to resolve problems systematically. Thus, DBL activities focus on working and designs which motivates students while making them proud of their achievements and building their confidence as thinkers, designers, and practitioners.

Furthermore, in earlier research on DBL use in middle-school science classrooms, success was judged to be based on how well collaboration, deep learning engagement, and trust between the teacher as facilitator and students took place [17]. In Finland, research also pointed out that technology alone was not enough and that there needed to be a concerted effort at developing new technological pedagogical and social infrastructure to serve its purpose [18]. In the United States, research was conducted on university student Extracurricular DBL (EDBL) from which the authors concluded that students build innovative self-efficacy from a process of successful task completion, social persuasion, and collaborative learning communities with clients, peers, industry professionals, and faculty [19]. Thus, from a review of these studies and authors we have summarized the DBL process into six steps including 1) needs identification, 2) design review, 3) information collection, 4) prototyping, 5) production, and 6) evaluation.

\subsection{Computational thinking skills (CTS)}

Computational thinking (CT) has been defined as skills that are used in problemsolving based on computer science [20], which sits at the core of every computing and engineering-related discipline [21]. Also, CT can be thought of as a skill while computer science can be thought of as an academic subject.

Also, the importance of computational thinking (CT) skills in early childhood education globally has been highlighted by Papadakis [22], who indicated that educators must not solely focus on a problem-solving process skills (CT) but instead provide children with new ways to express themselves, which supported their cognitive, linguistic, and socio-emotional development (Computational Fluency-CF).

Moreover, CTS has been stated to entail reflection, coding, design, analysis, and application, which constitute the scientific methods for computer scientists [21]. Program coding is also an important tool for fostering fundamental CTS, which addition- 
ally includes systematic and logical thinking and error recognition and inspection [23]. CT can also be considered a general problem-solving framework which involves skills, knowledge, or approaches to problem solving and coding to support these tasks and concepts [22], [25].

Furthermore, when we analyzed the literature concerning CTS we noticed a pattern in which four major categories of skills arose. These included the ability to facilitate problem-solving by decomposing/breaking down data, processes, or problems into smaller, manageable units which for this study we have labeled as 'decomposition'. The next element that was frequently mentioned was the pattern observation, associated trends, and data regularity which we have labeled as 'pattern recognition.' The third element was the ability to identify and prioritize individual components of a problem or task which we have labeled as the 'abstraction.' Abstraction has also been stated as the most essential and highest-level thought process in CT [6]. The fourth and final CTS element we identified with great frequency was the use of clearly defined steps in a problem's resolution or thought of in another way, the input and output. Thus, we labeled this component as the 'algorithm design' [3], [6], [10], [25-32].

\subsection{Waterfall model programming concept}

The Waterfall Model is an early concept adapted from the construction and manufacturing industries for use in software development. The first formal use of the term 'waterfall' has subsequently been attributed to an article written in 1970 by Winston Royce [33]. Although there are multiple iterations of the number of tiers and what each tier is called, for purposes of this paper we have identified five steps including 1) planning, 2) system analysis, 3) design, 4) system development and 5) system maintenance [12]. Although this model is an early concept in computer programming, many researchers continue to apply it as part of programming research as it meets user requirements as user inquiries are made and requirements agreements are documented to achieve mutual understanding [34] - [37].

\subsection{Participatory action research (PAR)}

Participatory action research (PAR) is a research methodology whose genesis can be found in the 1940s in which both the researchers and study participants identify a problem and jointly work together to find a solution. The PAR process also has the potential to empower people to increase their control over their lives.

Studies have also found that PAR is an effective tool for instructors and students to work together, whose research protocol often uses simple descriptive statistics and descriptive analysis to describe the data [13], [14], [38].

Also, numerous researchers who use PAR in their research become involved in the activities from beginning to end. Finally, in the process of adopting PAR for our study, we chose concepts outlined by authors including Kemmis and McTaggart as the main theoretical framework [12], [38] - [40]. Under their framework, we identified the importance of the development of a plan for improvement (planning) and the planning implementation for the teaching environment (practice). Also, we 
noted the need for 'observation' by each researcher including any input from the effects of the research's outcomes. Finally, the fourth tool is 'reflection', which includes the time to reflect on what has transpired including the evaluation and suggestions for improvement in the next round. The use of these steps to the end of the process will result in a real and accurate solution to the problem, which has been visually outlined in Figure 1.

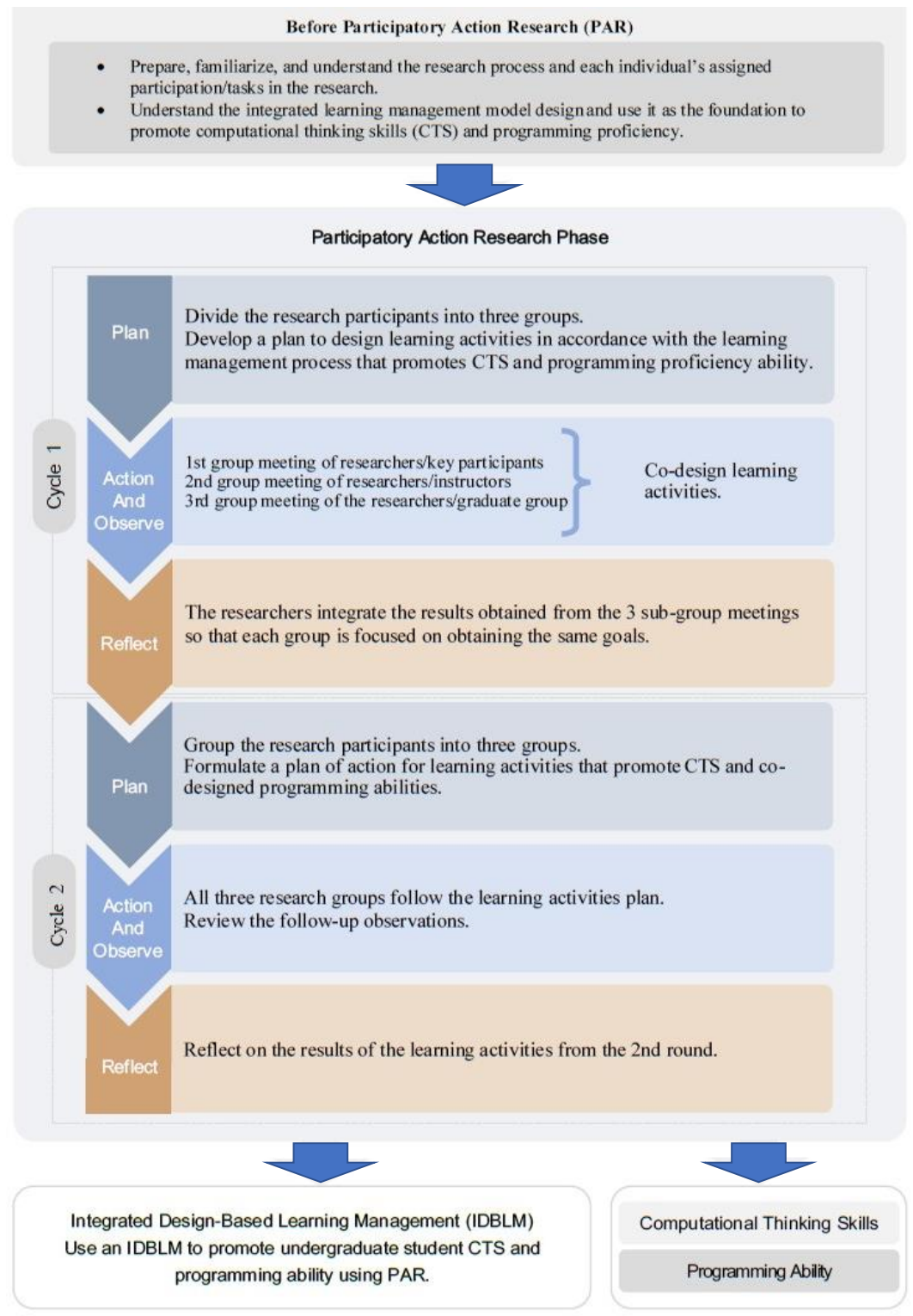

Fig. 1. A conceptual framework for undergraduate CTS and programming ability skills 


\section{Methods}

The researchers used a systematic review process to collect documents, books, textbooks, research papers and various types of international and domestic literature related to design-based learning management (DBLM), computational thinking skills (CTS), and the development of a conceptual framework using participatory action research (PAR) to synthesize documents to arrive at the elements necessary for developing programming skills. Thus, systematic reviews are based on clearly formulated questions which identify relevant studies, appraise their quality and summarize the evidence by use of explicit methodology [42].

Moreover, reliable and reputable online databases such as EBSCO, eBook Collection, ProQuest, Dissertation Theses, SpringerLink, Science Direct eBook and Scopus were used by the researchers. The sources were then divided into two levels (1) book research and (2) study from research papers, articles and academic writing papers. The researchers then examined the credibility of the data by considering the source of the documents. The documents initially collected had five Thai language papers and 37 foreign language papers in English, with all documents dated from 2010 to 2020.

From this systematic review partial results of this study and research were obtained. Moreover, the design-based integrated learning management model is based on the computational thinking skills of undergraduate students with a combination of participatory action research.

\subsection{Ethics clearance}

Before the implementation of the study, ethics clearance (EC) was obtained from the university's Human Research Ethics Committee and was granted certificate number EC-KMITL_64_053. After which, each of the study's 27 volunteer participants (21 students and six instructors) was assured of the confidential nature of their participation and were additionally informed they could withdraw at any time should they wish to do so.

\subsection{Participants and location}

In conducting this study, we divided the research participants into multiple groups consisting of the following:

- Group 1: This group consisted of 21 students in the Computer Studies Department of the Faculty of Education at Dhonburi Rajabhat University (Thailand) in semester 2 of the academic year 2020 .

- Group 2: This group consisted of three software programming instructors with at least 5 years of teaching experience.

- Group 3: This group consisted of three individuals who had graduated from the Computer Studies Department of the Faculty of Education at Thonburi Rajabhat University (Thailand) with excellent grades in software programming. 


\subsection{Standards assessment group}

In addition to these three groups who participated in the actual study, there was an additional group of nine experts who volunteered their time using a panel format to conduct an educational standards assessment as outlined from the work of Stufflebeam's 'Standards of Practice for Evaluators' [43]. These included a utility standard, an accuracy standard, a propriety standard, and a feasibility standard.

\subsection{PAR methodology}

It was determined that the most effective use of the PAR process was to use a round of four steps each, linked to the concept of design-based learning management, the waterfall programming concept, and the development of CTS and programming skills proficiency.

\subsection{Research period}

The study allocated 20 hours of classroom time over five weeks to conduct the research and to maximize each participant's benefits. Additionally, from the integration of the PAR process in determining activities in each step, we then conducted an assessment of the appropriateness of the learning management model developed from the integration of knowledge as previously outlined.

After we completed the standards assessment of the appropriateness of the learning management model in all four areas, we then proceeded to design learning activities. The input was then taken from the data collected from the experts' brainstorming session and operational review. From this, it was suggested that each activity be recorded using various techniques including audio, video, and photos.

\subsection{Research rounds}

In this research, the researchers conducted two rounds of participatory action research (PAR). Round 1 was used to jointly find the needs of the learners in order to allow each group to jointly design activities to solve common problems from different perspectives of each group. In Round 2, the students participated in a five-week activity-based learning management process. At the end of each week, each instructor collects the data from their observations and measures each students' results for each weeks' 5-session, 5-hour program. Finally, a potential third round is possible if from the reflection and analysis of the results from Rounds 1 and 2, the learners wish to repeat their activities and develop themselves further.

\subsection{Working groups}

Moreover, Figure 2 visually depicts the result details from the joint planning undertaken by the three group meetings and the participants including the student participants, the teachers, and the study's authors. All the participants in the study had vary- 
Paper-An Integrated Design-Based Learning Management Model to Promote Thai Undergraduate...

ing properties in terms of knowledge, experience, qualifications, and maturity. Therefore, it was agreed from the initial meeting that there should be a division into three groups allowing each group to jointly design activities to solve common problems from different perspectives of each group. We were then able to summarize the results from the three sub-meetings to better summarize the design of the learning activities to be included in the LMM. 


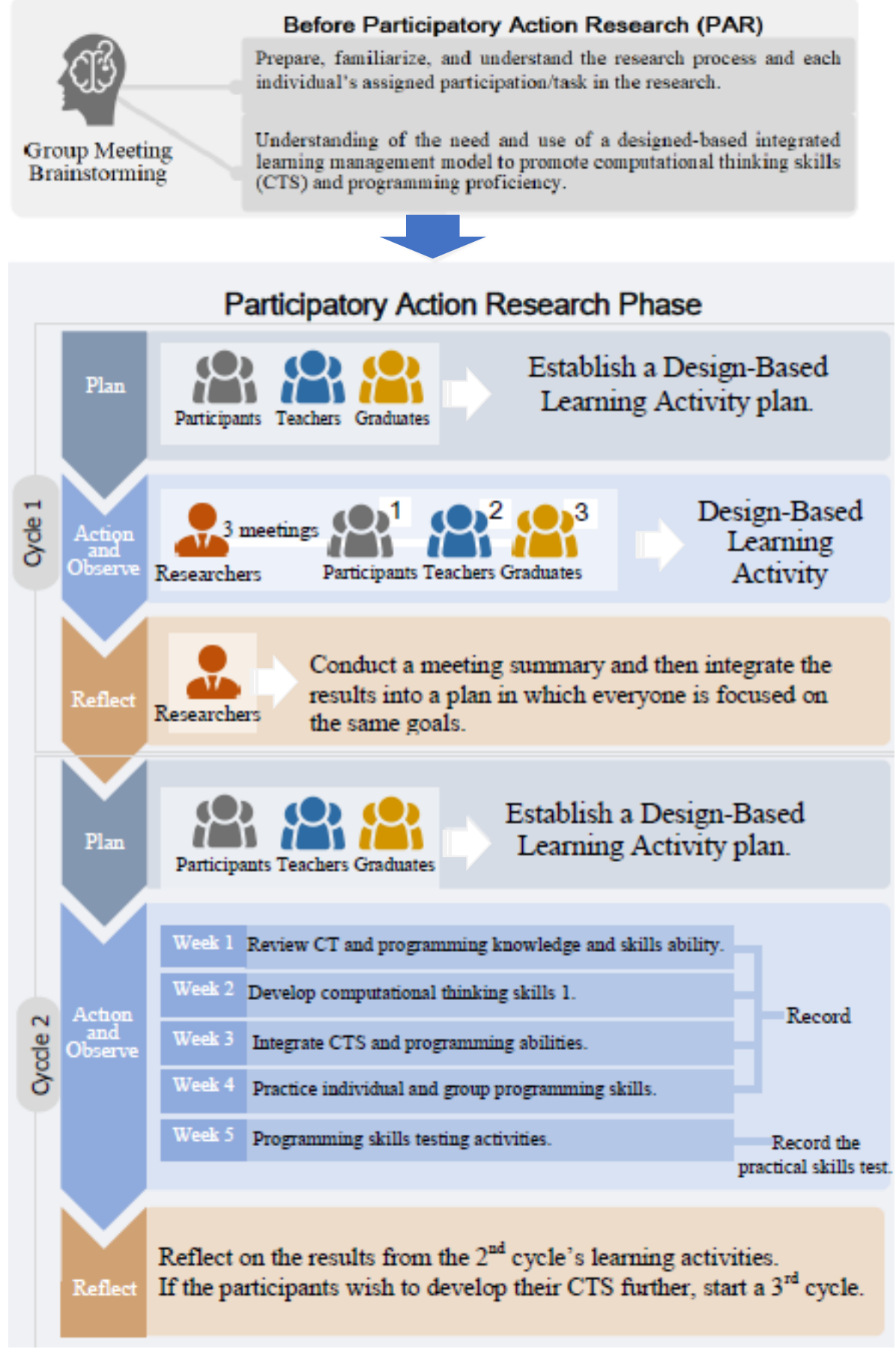

Fig. 2. Participatory action research implementation process for CTS and programming ability skills 
Paper-An Integrated Design-Based Learning Management Model to Promote Thai Undergraduate...

\subsection{Group 1 summary}

From each individual's LMM input who participated in Group 1's meeting, it was agreed that initial activities should be focused on obtaining knowledge concerning how much and at what level each student's CTS and programming abilities were. Therefore, this would require different types of worksheets as well as diverse activities that could be carried out by one person or group activity to obtain different perspectives.

\subsection{Group 2 summary}

From each individual's LMM input who participated in Group 2's meeting, it was determined that a successful LMM should let learners practice CTS that results in their ability to write programs. As such, the group felt that these skills could be obtained from a variety of jointly designed activities, with each student's CTS achievement obtained from each activity monitored in parallel. The monitoring process could either be undertaken by an instructor or a graduate who could mentor each student and guide them in ways to solve problems.

\subsection{Group 3 summary}

From each individual's LMM input who participated in Group 3's meeting, it was determined that there should be activities that encourage students to practice repetitive CTS. From the summary of the ideas from Group 3, five main activities for CTS and programming ability promotion ability were established. These consisted of 1) A review of each student's knowledge of CTS, 2) development of each student's CTS, 3) integration of CTS and programming knowledge, 4) practical skills training, and 5) testing of each student's practical skills by writing a program that is inserted into the LMM process.

\subsection{Four-step process}

Moreover, according to the PAR process, each round is supposed to consist of four steps including planning, action, observation, and reflection (Figure 2). These include:

Step 1- In the planning phase, there was a meeting in which the researchers, the student participants, and the teachers jointly formulated a plan for organizing learning activities which is suitable for each participant and consistent with each step of the learning management process.

We then organized three group meetings concerning the proposed LMM. In the meeting the participants developed design activities following each step of the learning process that encourages student CTS and programming abilities as depicted in Figure 2. These included the first meeting between the researchers and the students, the second meeting between the researchers and the teachers, and finally, a third meeting between the researchers and the former student programming graduates. 
Thereafter, we combined the results obtained from the three group meetings into a single model.

Step 2- Step 2 consisted of following the action plan and bringing the plan together for its implementation.

Step 3-Step 3 consisted of observing the results of the implementation of the plan.

Step 4-Step 4 consisted of the evaluation and reflection of the observation results, taking any problems that arise and resolving these in the next round, making it easier to understand.

In conducting this research, there may be obstacles from learners who may withdraw during research due to personal activities or becoming discouraged in learning activities based on a five-week schedule, preventing them from participating every time. However, the researchers made efforts to solve these issues by adjusting the sample during the activities which did not affect the research results.

\section{$4 \quad$ Results}

From the input from the multiple meetings, we applied concepts of computational thinking, waterfall programming, and design-based learning management combined with a PAR methodology to obtain an integrated designed-based learning management model to promote CTS and programming ability. Thereafter, two rounds were used in which the PAR process was embraced. Results from these rounds are as follows:

\subsection{Round 1}

Round 1 used an investigation based on the utilization of the PAR process. From this, three group meetings were held which consisted of individuals with various qualifications in terms of knowledge, experience, qualifications, and maturity. As such, a jointly formulated plan using a design-based learning management model (DBLMM) with activities promoting CTS and programming abilities was conceptualized. Moreover, each group meeting recorded audio of the conversations which helped in the design and integration of activities to promote learning activities during the next round.

\subsection{Round 2}

The researchers used the integration results from Round 1's meetings to integrate the results into a revised DBLMM. This resulted in the identification of five activities to promote learning including 1) knowledge review of CTS and programming ability, 2) CTS development, 3) integration of CTS and knowledge in programming, 4) practice skills, and 5) a programming skills practice test totaling 20 hours for all five elements. 


\subsection{Educational standards assessment results}

To obtain quality research, the researchers conducted an assessment of the appropriateness of the integrated DBLMM by adopting precepts laid out from extensive research and writings from D. L. Stufflebeam who is quoted as having said that, "The most important purpose of program evaluation is not to prove, but to improve" [43] [46]. Embracing these ideas, the nine experts were tasked to give their input on the context, input, process, and product of the LMM using the four educational assessment standards detailed in Table 1.

Table 1. Appropriateness of an integrated DBLMM to promote CTS and programming ability of students through PAR

\begin{tabular}{|c|c|c|c|}
\hline Assessment item & $\bar{x}$ & SD & Quality Level \\
\hline 1. Utility Standards & 4.41 & 0.34 & High \\
\hline $\begin{array}{l}\text { 1.1. The learning management model (LMM) can build a body of knowledge } \\
\text { about the theory of computational thinking and programming ability. }\end{array}$ & 4.22 & 0.44 & High \\
\hline $\begin{array}{l}\text { 1.2. The LMM can complement the knowledge and build practical skills } \\
\text { related to programming ability. }\end{array}$ & 4.00 & 0.00 & High \\
\hline $\begin{array}{l}\text { 1.3. From the use of the LMM, participants should be able to apply their } \\
\text { knowledge about theory and practice to computational thinking and pro- } \\
\text { gramming abilities. }\end{array}$ & 4.00 & 0.00 & High \\
\hline $\begin{array}{l}\text { 1.4. The proposed LMM can be used to study the development and problem- } \\
\text { solving effects of practical skills related to programming ability. }\end{array}$ & 4.11 & 0.60 & High \\
\hline $\begin{array}{l}\text { 1.5. The proposed LMM can be used to manage participant learning in en- } \\
\text { hancing CTS and programming ability. }\end{array}$ & 4.22 & 0.67 & High \\
\hline 2. Feasibility Standards & 4.18 & 0.44 & High \\
\hline $\begin{array}{l}2.1 \text { The methods used in the development of the LMM are suitable for the } \\
\text { context of the participants }\end{array}$ & 4.22 & 0.44 & High \\
\hline $\begin{array}{l}2.2 \text { The proposed LMM will encourage participants to develop their CTS and } \\
\text { programming abilities. }\end{array}$ & 4.00 & 0.00 & High \\
\hline $\begin{array}{l}2.3 \text { The proposed LMM will be able to address the lack of CTS and pro- } \\
\text { gramming abilities in participants. }\end{array}$ & 4.22 & 0.44 & High \\
\hline $\begin{array}{l}\text { 2.4 As a result of the proposed LMM, the participants will better understand } \\
\text { the problem in lacking CTS and programming abilities. }\end{array}$ & 4.11 & 0.60 & High \\
\hline $\begin{array}{l}2.5 \text { The proposed LMM will help the participants to better develop a piece of } \\
\text { work resulting from better CTS and programming ability. }\end{array}$ & 4.33 & 0.71 & High \\
\hline 3. Propriety Standards & 4.24 & 0.48 & High \\
\hline $\begin{array}{l}\text { 3.1 Each step of the learning management process is appropriate for creating } \\
\text { results that are following the objectives or goals set }\end{array}$ & 4.22 & 0.44 & High \\
\hline $\begin{array}{l}3.2 \text { The proposed LMM is appropriate for the application of knowledge in } \\
\text { theory for both CTS and the programming abilities of learners. }\end{array}$ & 4.22 & 0.44 & High \\
\hline $\begin{array}{l}3.3 \text { The proposed LMM is suitable for developing CTS and programming } \\
\text { abilities. }\end{array}$ & 4.11 & 0.33 & High \\
\hline $\begin{array}{l}3.4 \text { The methods used in the development of the proposed LMM are suitable } \\
\text { for the context of the learner. }\end{array}$ & 4.44 & 0.53 & High \\
\hline $\begin{array}{l}3.5 \text { The proposed LMM's concepts and theory serve as a good base to pro- } \\
\text { mote CTS and the programming ability of learners. }\end{array}$ & 4.22 & 0.67 & High \\
\hline 4. Accuracy Standards & 4.41 & 0.50 & High \\
\hline
\end{tabular}


Paper - An Integrated Design-Based Learning Management Model to Promote Thai Undergraduate...

\begin{tabular}{|l|c|c|c|}
\hline \multicolumn{1}{|c|}{ Assessment item } & $\overline{\boldsymbol{x}}$ & SD & Quality Level \\
\hline $\begin{array}{l}\text { 4.1 Applying the concepts of a design-based learning management } \\
\text { (DBLMM) computational thinking framework, a Waterfall programming } \\
\text { conceptual framework, and PAR are well integrated for the proposed devel- } \\
\text { opment of an LMM that meets the stated objectives. }\end{array}$ & 4.56 & 0.53 & Highest \\
\hline $\begin{array}{l}\text { 4.2 The development of the proposed integrated design-based LMM which } \\
\text { promotes CTS and programming abilities were correctly derived from the } \\
\text { synthesis and integration of knowledge according to the conceptual frame- } \\
\text { work. }\end{array}$ & 4.44 & 0.53 & High \\
\hline $\begin{array}{l}\text { 4.3 The development of the proposed integrated design-based LMM which } \\
\text { promotes CTS and programming abilities' data was systematically collected, } \\
\text { analysed, and reported. }\end{array}$ & 4.22 & 0.44 & High \\
\hline \begin{tabular}{l} 
Average for all four educational assessment standards \\
\hline
\end{tabular}
\end{tabular}

Results from the nine experts' assessments detailed in Table 1 show that the appropriateness of the LMM in all four standards aspects was at a high level $(\bar{x}=4.23, \mathrm{SD}$ $=0.44)$. When each of the four educational assessment criteria was viewed, it was determined that the utility standard level $(\bar{x}=4.41, \mathrm{SD}=0.34)$ and accuracy standard level $(\bar{x}=4.41, \mathrm{SD}=0.50)$ were both ranked similarity highest. They were followed by propriety standard $(\bar{x}=4.41, \mathrm{SD}=0.50)$ and lastly, feasibility standard $(\bar{x}$ $=4.41, \mathrm{SD}=0.50)$. Finally, it is noteworthy to find that overall the experts felt that the integration of the DBLMM computational thinking framework, the Waterfall programming conceptual framework, and the PAR were well-integrated and met the study's stated objectives $(\bar{x}=4.56, \mathrm{SD}=0.53)$.

\section{Discussion}

For this study the researchers used participative action research methodology and integrated it with relevant theoretical frameworks, including design-based learning management, waterfall programming, and computational thinking. However, in conducting research with PAR, there were limitations on various issues, namely the level of knowledge of the student sample group, the duration of participation in the four moments of action research (Plan, Act, Observe and Reflect - PAOR) process in each round for the students, graduates, and instructors [41].

Moreover, as suggested in the step-by-step guide to planning critical PAR projects, investigators must first make use of a planning phase in which meetings of participants is undertaken. In these meetings there must be understanding and agreement concerning the research process and the participants' agreement about participating from beginning to final completion. From these processes, the researchers found two main issues which are discussed as follows:

\section{$5.1 \quad$ Issue 1}

From our implementation of the participatory action research process, it was determined that each researcher, co-investigator, and participant should have equal status in the conceptualization, participation, and joint evaluation of each step during the 
pre-research stage. From this, it was determined that the PAR process should initially consist of 2 rounds, each consisting of 4 steps.

\section{Round 1}

Planning process. We divided the research participants into three groups, who were responsible for defining activities to promote learning management that promoted CTS and programming ability.

Planning and observation process. After we divided the participants into three groups, meetings were held to obtain additional design activities in promoting learning management. We then collected data from the three groups' meetings and integrated them into a unified LMM, which resulted in the definition of the following five learning activities:

1. Activities to review knowledge of CTS and programming ability.

2. Activities to develop CTS.

3. Activities to integrate CTS and programming knowledge.

4. Skills training activities for both individual and group programming practice.

5. Programming skills testing activities presented in the reflection process.

\section{Round 2}

Planning process. Once again, we again divided the planning process into the same three groups used in the first round, with the participants again tasked with formulating a plan to implement learning activities that promoted CTS and the ability to program together.

Designed procedures and observations. We designed the learning activities for five weeks, five hours each, based on the five activities that were jointly designed. In doing each activity, the effectiveness of each activity was measured by taking notes, worksheets, and practice skills.

Reflection process. From the procedure, we used the data recorded from various achievement measurements together to reflect on the participants of the learning activities in Round 2 and if the research participants wished to develop their CTA and programming abilities by entering the third round by repeating the same process as the second round.

The participatory action research (PAR) process. The PAR process resulted in the acquisition of learning that enabled undergraduate student participants to develop CTS and programming proficiency following the research methodologies based on various concepts [10], [13], [14], [47], [48].

The resultant outcome was that the research group jointly participated in finding a model which offered CTS and programming skill training solutions which encouraged the research participants to learn together to develop activities based on common needs.

\section{$5.2 \quad$ Issue 2}

The IDBLMM to promote CTS and programming abilities of undergraduate students used a PAR methodology and was integrated from the conceptual framework used in the research. The model's suitability assessment was confirmed by nine ex- 
perts on a case-by-case basis. It was found that in every aspect it was determined that there was a high level of suitability to the proposed model, conforming to the theory practically and consistently [43] - [46]. These results are also consistent with another Thai study in which the four assessment standards were used to assess the robustness of a proposed learning model [48].

However, it has been pointed out that Papadakis [49], that the use of methodologies for assessment by 'educational for children apps' must be carefully considered as many apps are lacking in terms of quality and do not meet age-appropriate and other pedagogical standards.

\section{Conclusion}

The study set out to embrace three research concepts/methodologies and integrate them into a learning management model to facilitate the development and promotion of Thai undergraduate students' computational thinking skills and programming abilities. First, the authors used design-based learning and integrated it with the commonly known and used Waterfall software development concept. These were then integrated into a participatory action research methodology in the hopes of obtaining greater input and collaboration in the development of the proposed model. After being evaluated by nine experts with expertise from a variety of related disciplines, including Curriculum and Instruction Programs, Educational Technology Programs, Teacher Professions, Computer Education Programs, Science and Technology Programs and experts in basic education science learning subject groups, the nine experts concluded that the proposed model had a high level of robustness.

It was further suggested that the proposed model be undertaken in five week sessions, of five hours each, using five exercises per week. Once again, in the adoption of the two rounds of Plan, Act, Observe and Reflect (PAOR) suggested for use in PAR [41], the researchers undertook the following:

In Round 1, the best PAR results are suggested by this study to come from understanding the importance of participating in the research from start to finish. It is also suggested that each session uses a co-researcher with different qualifications, in terms of knowledge, experience, qualifications and maturity. After that, the participants should jointly formulate a plan to design learning activities in accordance with the learning management process. It is also suggested that meetings should be limited to a small number of participants, in which audio is recorded from the meeting proceedings. Participants should then review their discussion and integrate those results into a unified format and direction.

In Round 2 activities to promote learning are undertaken. These include: 1 ) reviewing knowledge, computational thinking skills and programming ability, 2) developing computational thinking skills, 3) integration of computational thinking skills and programming knowledge, 4) practical skills practice, and 5) programming skills testing. This process is divided into 5 weeks of 4 hours each, totaling 20 hours in total. 
Each week after the designed activity, the researchers provide an assessment form to each unit supervisor to record a follow-up and practical skill test assessment to determine each learner's achievement during Round 2.

Round 3 concerns the willingness of the students to participate in an additional round to further their skills.

In doing each activity, the effectiveness of each activity is to be measured by taking notes, worksheets, and practice skills. The resultant outcome is that the groups jointly participated in finding a model which offered CTS and programming skill training which encouraged the participants to learn together to develop activities based on common needs. The outcome from the study is the plan to use this management model in future courses.

\section{$7 \quad$ References}

[1] Saad, A, "Students' computational thinking skills through cooperative learning based on hands-on, inquiry-based, and student-centric learning approaches," Universal Journal of Educational Research, vol. 8, no. 1, pp. 290 - 296, 2020. [Online serial]. Available: https://doi.org/10.13189/ujer.2020.080135 [Accessed Dec. 15, 2021].

[2] J. Voogt, P. Fisser, J. Good, P. Mishra, \& A. Yadav, "Computational thinking in compulsory education: Towards an agenda for research and practice," Education and Information Technologies, vol. 20, no. 4, pp. 715 - 728, 2015. [Online serial]. Available: https://doi.org /10.1007/s10639-015-9412-6 [Accessed Dec. 15, 2021].

[3] M. Lodi and S. Martini, "Computational thinking, between Papert and Wing," Science \& Education, vol. 30, pp. 883 - 908, 2021. [Online serial]. Available: https://doi.org/10.1007 /s11191-021-00202-5 [Accessed Dec. 15, 2021].

[4] J. M. Wing, "Computational thinking," Communications of the ACM, vol. 49, no. 3, pp. 33 - 35, 2006. [Online serial]. Available: https://doi.org/10.1145/1118178.1118215 [Accessed Oct. 7, 2021].

[5] J. M. Wing, "Computational Thinking Benefits Society," Social Issues in Computing, 2014. [Online serial]. Available: https://tinyurl.com/naf98wh8 [Accessed Dec. 15, 2021].

[6] S. Pipitgool, P. Pimdee, S. Tuntiwongwanich, \& A. Narabin, "Enhancing student computational thinking skills by use of a flipped-classroom learning model and critical thinking problem-solving activities: A conceptual framework," Turkish Journal of Computer and Mathematics Education, vol. 12, no. 14, pp. 1352 - 1363, 2021. [Online serial]. Available: https://tinyurl.com/2bdmyjta [Accessed Oct. 7, 2021].

[7] E. N. Caeli and J. Bundsgaard, "Computational thinking in compulsory education: A survey study on initiatives and conceptions," Educational Technology Research and Development, vol. 68, no. 1, pp. 551 - 573, 2020. [Online serial]. Available: https://doi.org/10. 1007/s11423-019-09694-z [Accessed Oct. 7, 2021].

[8] T. C. Hsu, "A study of the readiness of implementing computational thinking in compulsory education in Taiwan," in Computational Thinking Education, S. C. Kong and H. Abelson, Eds. Springer, 2019. [Online serial]. Available: https://doi.org/10.1007/978-981-136528-7_17 [Accessed Oct. 7, 2021].

[9] P. Prommun and T. Kantathanawat, "The development of an integrated design-based learning model, based on computational thinking for undergraduate students with participatory action research," International Journal of Innovation, Creativity and Change, vol. 
Paper-An Integrated Design-Based Learning Management Model to Promote Thai Undergraduate...

13, no. 1, pp. 1505 - 1518, 2020. [Online serial]. Available: https://tinyurl.com/nubk2532 [Accessed Dec. 15, 2021].

[10] A. O. Elfaki and Z. Bassfar, "Construction of a software development model for managing final year projects in information technology programmes," International Journal of Emerging Technologies in Learning, vol. 15, no. 21, pp. 4 -23, 2020. [Online serial]. Available: https://doi.org/10.3991/ijet.v15i21.15401 [Accessed Oct. 7, 2021].

[11] S. Pikdesree, "The comparative study of collaborative learning and SDLC Model to develop IT group projects," TEM Journal, vol. 6, no. 4, pp. 800 - 809, 2017. [Online serial]. Available: https://doi.org/10.18421/TEM64-20 [Accessed Dec. 15, 2021].

[12] S. Kemmis, R. McTaggart, and R. Nixon, The action research planner: Doing critical participatory action research, Springer Science \& Business Media, 2014. [Online]. Available: https://doi.org/10.1007/978-981-4560-67-2_5 [Accessed Dec. 15, 2021].

[13] A. J. Marrow, The practical theorist: The life and work of Kurt Lewin, Teachers College Press, 1977.

[14] S. Chandrasekaran and R. Al-Ameri, "Assessing team learning practices in project/design based learning approach," International Journal of Engineering Pedagogy, vol. 6, no. 3, pp. 24 - 31, 2016. [Online serial]. Available: http://dx.doi.org/10.3991/ijep.v6i3.5448 [Accessed Dec. 15, 2021].

[15] S. Chandrasekaran, A. Stojcevski, G. Littlefair, \& M. Joordens, "Project-oriented designbased learning: Aligning students' views with industry needs," International Journal of Engineering Education, vol. 29, no. 5, pp. 1109 - 1118, 2013. [Online serial]. Available: https://tinyurl.com/3hp83h36 [Accessed Dec. 15, 2021].

[16] J. L. Kolodner, P. J. Camp, D. Crismond, B. Fasse, J. Gray, J. Holbrook, S. Puntambekar, and M. Ryan, "Problem-based learning meets case-based reasoning in the middle-school science classroom: Putting learning by design(tm) into practice," Journal of the Learning Sciences, vol. 12, no. 4, pp. 495 - 547, 2003. [Online serial]. Available: https://doi.org/10. 1207/s15327809jls1204_2 [Accessed Dec. 15, 2021].

[17] P. Seitamaa-Hakkarainen, "Design based learning in crafts education: Authentic problems and materialization of design thinking," in Design Learning and Wellbeing, H. Ruismäki and I. Ruokonen, Eds. Dept. of Teacher Education, University of Helsinki, 2011, pp. 3 14.

[18] E. M. Gerber, J. M. Olson, \& R. L. Komarek, "Extracurricular design-based learning: Preparing students for careers in innovation," International Journal of Engineering Education, vol. 28 , no. 2 , pp. 317 - 324, 2012. [Online serial]. Available: https://tinyurl.com/dfxr9z8 [Accessed Oct. 7, 2021].

[19] J. Figueiredo and F. J. García-Peñalvo, "Improving computational thinking using follow and give instructions," In proc. 5th International Conference on Technological Ecosystems for Enhancing Multiculturality, 2017. [Online serial]. Available: https://doi.org/10.1145/3 144826.3145351 [Accessed Oct. 7, 2021].

[20] P. Silapachote and A. Srisuphab, "Engineering Courses on Computational Thinking Through Solving Problems in Artificial Intelligence,” International Journal of Engineering Pedagogy, vol. 7, no. 3, pp. 34 - 49, 2017. [Online serial]. Available: https://doi.org/10. 3991/ijep.v7i3.6951 [Accessed Dec. 15, 2021].

[21] A. Csizmadia, P. Curzonm M. Dorling, S. Humphreys, T. Ng, C. Selby, and J. Woollard, "Computational Thinking: A Guide for Teachers," Computing At School, 2015. [Online]. Available: https://tinyurl.com/4b25yd2p [Accessed Dec. 15, 2021].

[22] S. Papadakis, "The impact of coding apps on young children computational thinking and coding skills. A literature review," Frontiers in Education, vol. 6, 657895, 2021. [Online serial]. Available: https://doi.org/10.3389/feduc.2021.657895 [Accessed Dec. 12, 2021]. 
Paper - An Integrated Design-Based Learning Management Model to Promote Thai Undergraduate...

[23] H. Partovi, "A comprehensive effort to expand access and diversity in computer science," ACM Inroads, vol. 6, no. 3, pp. 67 - 72, 2015. [Online serial]. Available: https://doi.org/ $10.1145 / 2807704$ [Accessed Dec. 15, 2021].

[24] Y.-H. Ching, Y.-C. Hsu, and S. Baldwin, "Developing computational thinking with educational technologies for young learners," TechTrends, vol. 62, no. 6, pp. 563-573, 2018. [Online serial]. Available: https://doi.org/10.1007/s11528-018-0292-7 [Accessed Dec. 12, 2021].

[25] A. Barate, L. A. Ludovico, and D. Malchiodi, "Fostering computational thinking in primary school through a LEGO-based music nation," Procedia Computer Science, vol. 112, pp. 1334 - 1344, 2017. [Online serial]. Available: https://doi.org/10.1016/i.procs.2017.08.018 [Accessed Dec. 15, 2021].

[26] CAS Barefoot, "Computational thinking,” 2014. [Online]. Available: https://edtechbooks. org/-Wy [Accessed Dec. 15, 2021].

[27] W. Chachiyo, P. Pimdee, and A. Sukkamart, "Synthesising a blended learning model with problem based learning for improving the computational thinking of junior high school students," International Journal of Innovation, Creativity and Change, vol. 13, no. 8, pp. 549 - 562, 2020. [Online serial]. Available: https://tinyurl.com/6d5s4489. [Accessed Dec. $15,2021]$.

[28] C. Chalmers, "Robotics and computational thinking in primary school," International Journal of Child-Computer Interaction, vol. 17, pp. 93 - 100, 2018. [Online serial]. Available: https://doi.org/10.1016/j.ijcci.2018.06.005. [Accessed Oct. 7, 2021].

[29] M. S. Goldman and M. S. Fee, "Computational training for the next generation of neuroscientists," Current Opinion in Neurobiology, vol. 46, pp. 25 - 30, 2017. [Online serial]. Available: https://doi.org/10.1016/j.conb.2017.06.007 [Accessed Dec. 15, 2021].

[30] ISTE, "Computational thinking for all," September 11, 2014. [Online]. Available: https://edtechbooks.org/-yE [Accessed Dec. 15, 2021].

[31] M. Kolodziej, "Computational thinking in curriculum for higher education," Theses and Dissertations. 807, 2017. [Online]. Available: https://digitalcommons.pepperdine.edu/ etd/807 [Accessed Dec. 15, 2021].

[32] H. Partovi, "Should computer science be a mandatory class in U.S. high schools?, 2017. [Online]. Available: https://tinyurl.com/vp69s9p7 [Accessed Dec. 15, 2021].

[33] W. W. Royce, "Managing the development of large software systems," In proc. IEEE WESCON, number 8, Los Angeles, 1970 pp. 328 - 338. [Online]. Available: https://tiny url.com/36cw454w [Accessed Oct. 7, 2021].

[34] A. A. A. Adenowo and B. A. Adenowo, "Software engineering methodologies: A review of the Waterfall Model and object-oriented approach," International Journal of Scientific \&Engineering Research, vol. 4, no. 7, pp. 427 - 434, 2013. [Online serial]. Available: https://tinyurl.com/wb8kday2 [Accessed Dec. 15, 2021].

[35] S. A. J. Khalaf and M. N. Al-Jedaiah, "Software quality and assurance in waterfall model and XP: A comparative study," WSEAS Transactions on Computers, vol. 7, no. 12, pp. 1968 - 1976, 2008. [Online serial]. Available: https://tinyurl.com/6b97cax4 [Accessed Dec. 15, 2021].

[36] M. Kramer, "Best practices in systems development liferound: An analysis based on the waterfall model," Review of Business \& Finance Studies, vol. 9, no. 1, pp. 77 - 84, 2018. [Online serial]. Available: https://tinyurl.com/5scuytvi [Accessed Dec. 15, 2021].

[37] M. Iqbal and M. Rizwan, "Application of 80/20 rule in software engineering Waterfall Model," 2009 International Conference on Information and Communication Technologies, pp. 223 - 228, 2009. [Online serial]. Available: https://doi.org/10.1109/ICICT.2009.52671 $\underline{86}$ [Accessed Dec. 15, 2021]. 
Paper-An Integrated Design-Based Learning Management Model to Promote Thai Undergraduate...

[38] R. McTaggart, Ed., Participatory action research: International contexts and consequences, Suny Press, 1997.

[39] S. Kemmis and R. McTaggart, The action research planner, Deakin University Press, 1988.

[40] S. Kemmis, R. McTaggart, and R. Retallic, The Action Research Planner, Springer, 2004. [Online]. Available: https://doi.org/10.1007/978-981-4560-67-2 [Accessed Dec. 12, 2021].

[41] A. Gogus, "Action research on learning," in Encyclopedia of the Sciences of Learning, N.M. Seel, Ed. Springer, 2012. [Online]. Available: https://doi.org/10.1007/978-1-44191428-6_488 [Accessed Dec. 15, 2021].

[42] K. S. Khan, R. Kunz, J. Kleijnen, and G. Antes, "Five steps to conducting a systematic review," Journal of the Royal Society of Medicine, vol. 96, no. 3, pp. 118 - 121, 2003. [Online]. Available: https://doi.org/10.1177/014107680309600304 [Accessed Dec. 12, 2021].

[43] D. L. Stufflebeam, "Standards of practice for evaluators," presented at the Annual Meeting of the American Educational Research Association, San Francisco, CA, April 16-20, 1986. [Online]. Available: https://tinyurl.com/32uzm374 [Accessed Dec. 15, 2021].

[44] D. L. Stufflebeam, "The CIPP Model for program evaluation," in Evaluation Models. Evaluation in Education and Human Services, vol. 6. Dordrecht: Springer, 1983. [Online]. Available: https://doi.org/10.1007/978-94-009-6669-7_7 [Accessed Dec. 15, 2021].

[45] D. L. Stufflebeam, "Egon Guba's conceptual journey to constructivist evaluation: A tribute," Qualitative Inquiry, vol. 14, no. 8, pp. 1386 - 1400, 2008. [Online serial]. Available: https://doi.org/10.1177/1077800408325308 [Accessed Dec. 15, 2021].

[46] D. L. Stufflebeam and C. L. S. Coryn, Evaluation: Theory, models and applications, 2nd ed., Jossey-Bass, 2014.

[47] L. Romyasamit and T. Kantathanawat, "Development of an instructional model based on self-reliance and inquiry-based instructional technique to enhance system analysis and design skills by applying participatory action research," PalArch's Journal of Archaeology of Egypt / Egyptology, vol. 17, no. 7, pp. 12049 - 12064, 2021. [Online serial]. Available: https://tinyurl.com/45hknut3 [Accessed Dec. 15, 2021].

[48] T. Tanhakorn and P. Pasunon, "Participatory action research for creative entrepreneurship development," Walailak Journal of Social Science, vol. 11, no. 2, pp. 45 - 76, 2018. [Online serial]. Available: https://tinyurl.com/56yn8chr [Accessed Oct. 7, 2021].

[49] S. Papadakis, "Advances in Mobile Learning Educational Research (AMLER): Mobile learning as an educational reform," Advances in Mobile Learning Educational Research, vol. 1, no. 1, pp. 1 - 4, 2021. [Online serial]. Available: https://doi.org/10.25082/AMLER. 2021.01.001 [Accessed Dec. 15, 2021].

\section{Authors}

Phattharapol Prommun is a doctoral student in the Computer Education Program in the School of Industrial Education and Technology at the King Mongkut's Institute of Technology Ladkrabang (KMITL) in Bangkok, Thailand. He graduated with a Bachelor of Business Administration (B.B.A) degree in Computer Business and a Master of Science (M.Sc.) degree in Science Education (Computer). He specializes in computer education, computer programming, web programming, computer graphics for education and computer networking (Email: 58603018@kmitl.ac.th, https://orcid.org/0000-0003-4896-5138). 
Paper-An Integrated Design-Based Learning Management Model to Promote Thai Undergraduate...

Thiyaporn Kantathanawat is an Associate Professor in the School of Industrial Education and Technology at the King Mongkut's Institute of Technology Ladkrabang (KMITL) in Bangkok, Thailand. She graduated with a B.S.W in Social Work, M.Ed. in Educational Research and Statistics and a Ph.D. in Applied Behavioural Science Research. She specializes in educational research, behavioural Science, educational psychology (Email: thiyaporn.ka@kmitl.ac.th, https://orcid.org/0000-00024436-8806).

Paitoon Pimdee is an Associate Professor with the School of Industrial Education and Technology at the King Mongkut's Institute of Technology Ladkrabang (KMITL) in Bangkok, Thailand. He graduated with a Bachelor of Economic in Economics and a Master of Science (M.Sc.) degree in Science education. He also holds a Ph.D. in environmental education and specializes in science education, environmental issues, energy conservation, and ecotourism (Email: paitoon.pi@kmitl.ac.th, https:// orcid.org/0000-0002-3724-2885

Thanate Sukkamart is a teacher at the Demonstration School with the Prince of Songkla University (Secondary), Faculty of Education, Prince of Songkla University, Pattani Campus in Thailand. He graduated with a Bachelor of Science in Education (B.Sc. in Ed.) and a Master of Science (M.Sc.) degree in physics education. He specializes in teaching physics and science education (Email: thanate.s@psu.ac.th, https://orcid.org/0000-0002-4718-3612).

Article submitted 2021-10-17. Resubmitted 2021-12-15. Final acceptance 2021-12-15. Final version published as submitted by the authors. 